\title{
Brasil: desafios e perspectivas
}

\author{
PAULO EVARISTO, CARDEAL ARNS
}

$\mathrm{D}$ ESAFIOS e perspectivas merecem análise do ponto de vista pessoal e coletivo. Ninguém deveria considerar-se dispensado de dar sua contribuição, sobretudo quando é possível transformar a crise em tentativas de solução ou ao menos em união de forças para a nova fase da História.

O editor de nossa Revista se lembrou provavelmente da minha condição de arcebispo que lutou por 28 anos em favor da liberdade e igualdade, da justiça social e da honestidade, como the mandavam os Livros Sagrados dos judeus e dos cristãos.

Por isso mesmo, considero o primeiro desafio a própria comunicação. Ela certamente influenciava os homens lá pelos anos de 3500 a.C., quando os textos passaram da transmissão oral à escrita, como nos ensinam muitos especialistas. Também acredito que Abraão, nosso Pai na fé, se comunicava lá pelos anos 1800 a.C. de maneira diversa daquela dos evangelistas que foram ajuntando as tradições das comunidades para transmiti-las aos tempos posteriores.

Ao preparar minha tese sobre o Livro segundo São Jerônimo, deparei com o fato surpreendente de Santo Agostinho, já célebre escritor, consultar o colega mais ousado, que se chamava Jerônimo, vejam bem, se de fato convinha abandonar o sistema da tradução juxta-linear por uma linguagem clássica e agradável aos ouvidos dos cristãos. Por sorte - dizemos nós - o papa Dâmaso era, além de amigo de Jerônimo, versado em rimas, cadências e até em composição de versos.

Qual é o desafio de hoje para a Bíblia penetrar na vida e convivência dos cidadãos das grandes metrópoles? Talvez sejam múltiplos os desafios. Há pouco, afirmava um especialista em comunicação que as TVs, rádios e os demais meios modernos de comunicação encontram diariamente, em São Paulo, mais de 10 mil fatos que deveriam levar como notícia ao povo. A luta consiste em descobrir e divulgar as que mais interessam à massa popular e fazê-lo de maneira ágil e original. Quando um ouvinte desse comunicador lançou a pergunta, quantas destas novidades visam à solidariedade $\mathrm{e}$ aos demais princípios cristãos, a resposta foi breve e decepcionante: "Nem um por cento, porque não se encontra patrocinador para mais." O Cristianismo deixa de ser Boa-Nova, ou seja "Evangelho". 
É verdade que, nos últimos tempos, tanto a Igreja em Roma quanto no Brasil se esforçou por alcançar ou acompanhar a evolução das comunicações. É exigência de Cristo e sua última recomendação em terra. Por que ainda não é a nossa?

Mas, há outros desafios que talvez despertem mais pessoas jovens para enfrentá-los. A desigualdade é o desafio brasileiro que mais espanta o mundo. Sua conseqüência mais direta é a fome. E o combate à fome é uma norma constitucional, uma obrigação do Estado e obrigação de todos. Como se não bastassem a fome, a concentração de renda e de terras, temos ainda a má distribuição da instrução.

O liberalismo político está na base da primeira experiência moderna de democracia e, infelizmente, nunca aconteceu na América Latina. O desafio é que o liberalismo econômico, que pode existir indepen-

\section{a dominação do mercado estrangula} os ideais democráticos ... dentemente da democracia, pode e ameaça abafar o ideário liberal, isto é, aquele que contempla as liberdades individuais, liga-se à soberania popular, abole a tortura, garante a não-retroatividade da Lei etc. Basta prestarmos atenção para o fato de que a dominação do mercado estrangula os ideais democráticos. A democracia de fato repousa sobre a soberania popular e o respeito aos direitos humanos. Nesta medida, um dos grandes desafios, hoje, está em sabermos desenvolver uma crítica de tudo o que avilte a pessoa humana.

Temos cerca de 50 milhões de pobres no Brasil e 21 milhões de indigentes. Os critérios que levam a considerar o que seja a pobreza variam de uma instituição para outra. Mas a realidade da pobreza certamente passa pelo conceito de desigualdade e do fato da privação. Creio que podemos considerar como pobre a pessoa privada de seus direitos fundamentais.

No Brasil, 48,7\% da renda está concentrada nas mãos dos $10 \%$ mais ricos (Banco Mundial, 1990), enquanto que os 10\% mais pobres detêm apenas $0,8 \%$ dela. À guisa de comparação vale lembrar que os $10 \%$ mais pobres da Alemanha detêm $9 \%$ da renda e os do Paraguai, 2,3\%. Como seria possível modificar tal anomalia?

São certamente indispensáveis os planejamentos. E planejamento só é digno deste nome quando leva à ação. No Brasil, tende-se a confundir planos com planejamentos e produtos com resultados, como bem observa o professor Alberto Teixeira, do Instituto de Planejamento do Ceará e diretor 
da Escola de Governo de Fortaleza. O resultado mais urgente que os planejamentos devem obter, no Brasil, é o que melhore a condição de vida dos excluídos propiciando a inclusão. E planejamento bem feito supõe etapas como:

- conhecer a realidade sobre a qual se quer atuar, com seu passado, diagnóstico presente e tendências futuras;

- desenhar um projeto, isto é, determinar o que fazer;

- elaborar atividades estratégicas que viabilizem o que se pretende fazer;

- efetuar uma ação concreta que transforme a realidade.

Dizer que certas áreas - saúde e previdência, por exemplo - estão em crise, é tentar não ver a presença de problemas estruturais, levando a intervenções de curto prazo, que apenas ofuscam mas não resolvem os problemas.

Outro problema, está no fato de o Brasil não efetuar importações seletivas, e de o Estado brasileiro tender a destruir, inclusive com certas privatizações, o próprio Estado brasileiro. Não se constrói uma nação com consumidores - como quer a política do mercado - mas com produtores e construtores de uma sociedade mais justa. Um liberalismo adequado atribui todas as atividades-fim à sociedade civil e todas as atividades-meio ao Estado.

Tomemos, como exemplo de política pública, a questão da Previdência Social. Como bem observam estudiosos, entre eles Amélia Cohn e Fábio Konder Comparato, a Previdência é uma política que, sendo social em sua essência, tem sofrido desvio ao ser tratada como mera política econômica. A desigualdade é o grande problema que a Previdência Social deveria enfrentar. No entanto, tudo o que vemos são políticas assistencialistas.

A Previdência Social é um imperativo ético, moral, e como tal é que deve ser visto e tratado. Mas, no Brasil, infelizmente, trata-se de uma política social que, como as demais, apenas reproduz a desigualdade da sociedade brasileira ao encaminhar-se para a desinstitucionalização dos direitos.

O Brasil foi essencialmente dinâmico com relação à criação de empregos no período compreendido entre os anos 30 e 70, especialmente a partir do término da Segunda Guerra Mundial, em 1945. Mas o crescimento do país à taxa de $7 \%$ ao ano, um dos maiores senão o maior índice mundial de crescimento - que o levou à $8^{\mathrm{a}}$ posição, atualmente $10^{\mathrm{a}}$, não garantiu melhor distribuição de renda - o que nos deixa no $74^{\circ}$ lugar no que se refere à qualidade de vida. Não garantiu melhor distribuição de renda especial- 
mente por conta do governo militar, que manteve o projeto desenvolvimentista das classes dominantes. Assim, a partir da década de 80, estamos nos defrontando com o agravamento do desemprego, fator determinante da expansão de moradores e meninos e meninas de rua em todas as cidades de grande ou médio porte do país.

\section{acabamos por computar um total de 18 milhóes de desempregados...}

Se a década de 80 marca o surgimento do desemprego, a de 90 assinala a desestruturação do mercado de trabalho. Foram 3,3 milhões de empregos perdidos no período, aos quais, acrescentando-se os 15 milhões

que deveriam ter entrado no mercado de trabalho, acabamos por computar um total de 18 milhões de desempregados. O que sucedeu no Brasil, nos anos 90 , foi algo tão perverso que desestruturou o empresariado nacional.

A desigualdade no Brasil está tão entranhada em nossa cultura que nos torna o único país a manter celas especiais para prisioneiros com nível universitário. Na política, as coisas não acontecem de maneira natural, nem inocente.

As reformas no país estão acontecendo sob a égide da lógica mercantil, mas, como Aristóteles já nos advertia, a sociedade política não é uma sociedade comercial e deve ter como objetivo a justiça construída através da solidariedade.

Apesar ou exatamente por causa de todos os desafios acima levantados, compartilho as opiniões respeitáveis do professor Antonio Candido. Somos ambos otimistas em relação ao Brasil. Em conversa recente, discorreu ele sobre o que chama de aspectos saudáveis, prováveis soluções para os desafios brasileiros a partir dos pontos de vista sociológico e histórico. Lembrou que, em 1933, Gilberto Freire já via a globalização e a comunhão inter-racial como algo que a xenofobia não conseguiria evitar. Enfim, para nós, a mistura de culturas e de raças prefigura o mundo futuro.

Como salutar herança portuguesa, podemos constatar a simplicidade da maioria da elite brasileira, da qual os que contrariam esta característica são minoria e nem sempre fazem parte da elite, mas são apenas novos ricos.

Também a resistência da população brasileira à hierarquia constitui um aspecto saudável para o mundo futuro. Sob este aspecto, vale lembrar que o Brasil instituiu a carreira militar em 1808, com forças armadas em que as promoções se dão através dos estudos, e foram menos violentas do que a de países como a Argentina e o Chile durante as ditaduras militares que 
assolaram a América do Sul nos anos 60 e 80. Felizmente, desde o início da redemocratização atual, estamos constatando uma diminuição progressiva do papel controlador do exército na vida sócio-política do nosso país.

Somos, ainda, o único país da América Latina a adotar uma carreira diplomática fechada, isto é, uma instituição a que se tem acesso somente através de concursos - rígidos, aliás - desde 1930. O Itamarati tem se notabilizado nas relações internacionais e foi capaz de resolver, ao menos até o momento e em que pese a preocupação do que possa vir a ocorrer na Colômbia, as questões das nossas fronteiras, de maneira diplomática e sem ter de recorrer ao nefando recurso da guerra.

Mestre Antonio Candido reportou-se ao Manifesto da Revista Clima (vide $\mathrm{n}^{\circ} 12$ da revista), totalmente redigido por Paulo Emílio Salles Gomes, em que este apontou para a existência do czarismo no mundo e para o fato de o cristianismo ter sido a primeira instituição, na história, a falar em igualdade. Lembrou ainda que Bossuet, em Cours de Histoire Universelle, afirmou que os povos melhoram quando mais se aproximam da justiça de Deus.

Precisamos tentar orientar o "acaso", ter ideologias claras de transformação na criação de políticas e culturas inclusivas, pois as mudanças são complexas; não há determinismo histórico e, tampouco, predestinação. Deus respeita demais a liberdade humana, para fazer da vida de qualquer homem algo que fuja ao gozo da liberdade. Deus respeita até a vontade do homem de afastar-se d'Ele, não se impondo, apenas nos convidando a amá-Lo e a servi-Lo. A história está nas mãos de Deus, mas concretamente em nossas mãos, todos criados à Sua imagem e semelhança. Enfim, o povo brasileiro traz em si sementes que poderão conduzi-lo à igualdade.

Necessária é também a criação de espaços públicos nos quais ocorra o debate qualificado, isto é, aquele que se dá entre os que realmente entendem dos assuntos em pauta, debate a serviço dos excluídos e não dos privilégios de grupos ou de meras parcelas da população. Mas, convém não esquecer: certas discussões, quer envolvam previdência ou saúde, quer educação, não serão, necessariamente, técnicas, mas antes políticas. Há que se implementar políticas que sejam negociadas com a sociedade e que se tornem independentes da gestão pública. Paralelamente, é imprescindível o controle público dos fundos, da arrecadação e das despesas públicas.

Torna-se inadiável a criação de empregos compensatórios para os desempregados pela tecnologia. Para tanto, há que se implementar o crescimento econômico da atividade estatal e da privada. Há que se criar instrumentos de proteção da pequena propriedade e eliminar o discurso consu- 
midor. Sirva-nos de exemplo a França, país que protege a pequena propriedade, proibindo inclusive a instalação de shoppings até mesmo em Paris, pois tais empreendimentos eliminariam as pequenas e pitorescas empresas de alimentação e congêneres, que compõem o perfil e o charme daquela cidade. Para fazer frente ao discurso consumidor, o Japão, por exemplo, não hesita em produzir o seu próprio arroz, recusando-se a importá-lo da Argentina, o que lhe custaria a metade dos gastos que tem para cultivá-lo.

Enfim, o Brasil precisa de um conjunto de políticas para a devida proteção de setores que são frágeis frente à concorrência. Em bom português, o Brasil precisa de políticas de proteção para os mais fracos. Indefesos, somos todos porque tivemos uma abertura econômica e financeira indiscriminada; com um discurso que, dispensando políticas regionais, incentivou a livre concorrência, outra balela que na verdade só é livre para os mais fortes.

A produtividade aumentou. De quem? Para quem?

Deixa-se de identificar a permanência de pessoas com valores antidemocráticos no cenário da política nacional. A melhor distribuição de renda não ocorre. Desacredita-se, culpa-se, com a maior sem-cerimônia, a democracia, nossa única possibilidade de uma vida mais justa.

Os compromissos sociais não têm passado de retórica. O combate à fome é uma norma constitucional. Uma série de obrigações estão previstas na Constituição e o seu não-cumprimento apenas evidencia crimes de lesapátria. Há que se regulamentar leis, implementar políticas que sejam inclusivas, democráticas, formadoras não só de uma cultura mas de uma realidade de vigência dos direitos humanos.

Para acabar com a pobreza há que se retomar o crescimento, distribuir a renda mediante políticas públicas de saúde, de educação, de transportes, entre outras, além de a distribuição patrimonial de habitação e da reforma agrária.

Precisamos não esquecer que a educação e qualificação não são meras necessidades econômicas, como querem certos economistas. São muito mais, constituem um direito fundamental e inalienável do ser humano.

Em países do primeiro mundo como Estados Unidos, Alemanha e Japão, a indústria ainda tem uma participação importante. Não podemos permitir ao mercado a liberdade que tem tido, precisamos politizar e democratizar as relações econômicas. 
Para sair do impasse, este país precisa de um consenso entre classes médias, classes trabalhadoras e alguns setores empresariais. Em outras palavras: precisamos de um projeto nacional que recomponha a estrutura produtiva, recuperando alguns aspectos saudáveis, para uma política inclusiva, da abertura brasileira. Precisamos de controle sobre o fluxo de capitais, protegendo alguns setores industriais por meio de regras públicas, de forma transparente e democrática, evitando falências e desemprego.

É impostergável a auditoria transparente e exata das dívidas externas e internas, para que se volte a aplicar, com vontade política e eficácia, no sentido de eliminar a exclusão social e reparar as injustiças, carências e desigualdades sociais. É mais do que hora de dizer um não, em nível internacional, à opressão dos mais ricos e às formas nem sempre explícitas de neocolonialismos.

Santa Catarina, meu estado natal, caracterizava-se pela pequena propriedade. Hoje é um grande latifúndio, fazendo com que os catarinenses migrem até para o Acre. É indispensável a Reforma Agrária de fato, que garanta o assentamento da população no campo, humanizando as cidades, eliminando as monoculturas e a fome de boa parte da população.

A concentração de bens nas mãos de poucos não é vontade de Deus. É um problema sócio-político, implicando mudanças de estruturas e de mentalidades.

O Brasil é o segundo país do mundo em índice de concentração de terra. Segundo o INCRA, Instituto Nacional de Colonização e Reforma Agrária, dois mil latifúndios ocupam uma área correspondente a duas vezes e meia a área do território do estado de São Paulo. O Estatuto da Terra, de 1965, completou 35 anos. Durante todo este tempo, os brasileiros aguardam a Reforma Agrária nele prevista. Além dos grandes proprietários, o lamentável é constatar intelectuais que consideram a Reforma Agrária como reivindicação ultrapassada.

A Reforma Agrária, sem dúvida alguma, será um grande fator de redistribuição de renda. Outro passo, a taxação dos mais ricos, tem sido polemizado em nome do princípio de igualdade e do respeito aos direitos humanos. De qualquer forma, há que se criminalizar o gasto excessivo em um país onde crianças vivem na rua e morrem de fome, enquanto ricos cometem atentados ao pudor público, à ética, à mais comezinha noção de solidariedade, esbanjando em futilidades. Vêm eles acompanhados pelos criminosos de colarinho branco que esvaziam os cofres públicos ou o mercado nacional. 
Repito e insisto que a Previdência Social, as aposentadorias, a assistência médica, a educação em todos os níveis (incluindo a pré-escolar) são dever do Estado e caracterizam-se como um problema moral e ético, jamais econômico. Por falar em econômico, quando se tem dinheiro para tantas malversações e se o sonega para a implementação da justiça social e do investimento na pessoa humana, o que se tem é um desgoverno, uma deseducação da sociedade como um todo.

As mentalidades são acríticas e, como tais, conservadoras. São elas que explicam discriminações, preconceitos e tantos outros comportamentos irracionais. Quanto ao Brasil, temos, infelizmente, paralelamente aos pontos que nos mantêm otimistas e já enumerados, a presença de uma forte mentalidade autoritária, escravagista, desigualitária, egoísta etc. Há que se criar um amplo projeto nacional de educação em todos os níveis, que leve o brasileiro a criticar e se conscientizar de sua mentalidade, para que possa eliminar o opressor introjetado que vive dentro de nós (conceito do meu saudoso amigo Paulo Freire).

A escola pública, em todos os graus e níveis, deve ter garantida a sua existência. Uma escola pública de qualidade e com professores devidamente qualificados e remunerados. A educação é dever do Estado, é direito humano fundamental.

a educação pública, no Brasil, vem sendo sucateada ... A educação pública, no Brasil, vem sendo sucateada e, a particular, na maioria das vezes, já é pura sucata. O analfabetismo no Brasil precisa ser erradicado de uma vez por todas e revalorizada a cultura do livro.

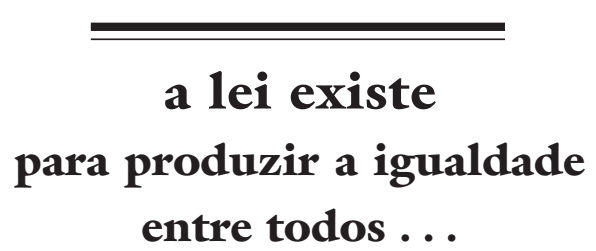

A ética de resistência democrática, no dizer de Betinho, baseia-se nos princípios de liberdade, igualdade, diversidade, participação e solidariedade. Esta ética tem, como características de ação, que o privado se subordine ao público; que o interesse comum da maioria se afirme respeitando a minoria; que a lei existe para produzir a igualdade entre todos e respeitar a diversidade e a liberdade como condições do exercício da cidadania.

Esta ética humaniza. Política e ética andam sempre juntas. A questão é saber para onde e para quem.

Exigência básica é a instauração da Civilização do Amor, já nos dizia o saudoso papa Paulo VI, o que requer a vigência dos direitos humanos (cerne 
da mensagem evangélica, acrescentava Sua Santidade), através da paz, da liberdade, da igualdade e da participação, isto é, da justiça social.

Embora voltada para Deus e mediada por Jesus Cristo, o centro da ética é todo e qualquer ser humano, único, irrepetível, insubstituível e necessário, enfim, o centro da ética é a dignidade humana. Esta afirmação conjunta do valor da pessoa, tanto por parte da sociedade laica quanto por parte das religiões, tem possibilitado diálogos, convivência e atuação. Mas ainda há muito a avançar...

Paulo Evaristo, cardeal Arns é arcebispo emérito de São Paulo. Escreveu O que é Igreja? (1981), Pensamentos (1982), Opção pelos pobres (1983) e o Prefácio do livro Brasil nunca mais (1985). 